\title{
How fear of violence drives intergroup conflict: Evidence from a panel survey in India*
}

\author{
Sebastian Schutte \\ Peace Research Institute Oslo \\ 0186 Oslo, Norway \\ sebastian@prio.org
}

\author{
Constantin Ruhe \\ Goethe University Frankfurt \\ 60323 Frankfurt, Germany \\ ruhe@soz. uni-frankfurt.de
}

\author{
Niranjan Sahoo \\ Observer Research Foundation \\ 110002 New Delhi, India \\ niranjansahoo@orfonline.org
}

Word count: 10,098

\begin{abstract}
Earlier research on ethnic and religious conflict has identified fear as an important motivation. While theoretically sound, this expectation has never been tested at larger scales in ongoing episodes of political violence. Instead, conceptual progress has been made in lab experiments. Combining insights from observational research and stylized experiments, we predict that fear for personal safety due to witnessed violence causes prejudice against outgroups, enhanced internal cohesion, and support for extremist actors. To test these predictions, we conducted surveys in the Indian State of Uttar Pradesh over three waves involving the same 783 respondents starting in January 2017. the surveys continued during the tense Legislative Assembly elections in the Spring. The results largely corroborate the theoretical expectations and present a hard in-vivo test of long-standing conjectures.
\end{abstract}

Keywords: India, conflict, panel survey, mobile reimbursement

\footnotetext{
${ }^{*}$ We owe a debt of gratitude to Susumu Shikano and Konstantin Käppner for excellent feedback on the MCMC estimations and to Alexander De Juan and Simon Munzert for great comments on an early draft. We would like to express gratitude for financial support to the German Foundation for Peace Research (DSF, Grant \#SP06/06-2015), the EU FP7 Marie Curie Zukunftskolleg Incoming Fellowship Program (Grant \#291784), and the Zukunftskolleg of the University of Konstanz. We would like to thank Raphael Susewind for his laudable open access provision of polling station-level demographic information. Finally, we would like to thank Rajeev Kumar of IIMR India for excellent management of the surveys in Uttar Pradesh.
} 


\section{Introduction}

Pondering their options after the swift, US-led occupation of Iraq in 2003, Al-Qaeda's higher echelons exchanged internal memos. Their stated long-term goal of removing the US presence from the Arab peninsula could be pursued by different means (see Wright 2007:295). Abu Musab alZarqawi opted to ignite a full-blown religious conflict between Sunni and Shia: "[i]f we succeed in dragging them into the arena of sectarian war, it will become possible to awaken the inattentive Sunnis as they feel imminent danger." ${ }^{1}$ Al-Zarqawi got his way: a string of sectarian attacks including the 2005 and 2006 Al-Askari Mosque bombings pushed the country over the brink. For the next three years, the conflict entered its most lethal phase, with casualty estimates in the hundreds of thousands, largely due to sectarian violence. ${ }^{2}$ More recently, ISIL persecuted religious minorities in Iraq and Syria, but also relied on terrorism with the explicit intention of disturbing the peaceful coexistience of Muslims and Christians in the West (Hussain 2015).

Far away from the murderous ambitions of violent extremists, benevolent researchers had taken note of the role fear can play in intergroup conflict a decade earlier. In the words of Lake and Rothchild (1996:41):

We argue instead that intense ethnic conflict is most often caused by collective fears of the future. As groups begin to fear for their safety, dangerous and difficult-to-resolve strategic dilemmas arise that contain within them the potential for tremendous violence [...] Ethnic activists and political entrepreneurs, operating within groups, build upon these fears of insecurity and polarize society.

Given the scholarly and anecdotal salience of fear as a driver of intergroup conflict, one would expect it to be an a prominent explanation for why groups participate in civil war today. However, this is not the case. Despite its prevalence in the 1990s, the study of fear as a driving force in intergroup conflict has plateaued and given way to structural explanations. Arguably, this is due to the empirical complications of measuring psychological states in ongoing episodes of political strife. Green and Seher (2003) argued most explicitly that individual-level sentiments play a crucial role in ethnic conflict, but lament the absence of suitable research designs:

\footnotetext{
${ }^{1}$ Abu Musab al-Zarqawi, strategic correspondence with the Al-Qaeda's high command, 2004. The full text is available at https://2001-2009.state.gov/p/nea/rls/31694.htm, last accessed March 5, 2019.

${ }^{2}$ For a comprehensive analysis of civilian and military casualties in Iraq from 2003 to 2008 see Carpenter et al. (2013).
} 
Rarely have social scientists endeavored to observe a set of people as their life circumstances change radically because of unfolding events [...] and never to our knowledge in the context of ethnic violence (page 526).

More than fifteen years later, this criticism stands unaddressed. Filling this gap, we ask the following research question: Does fear of violence cause prejudice, cohesion, and support for in-group extremism in an ongoing communal conflict? We address this question by running reimbursed electronic surveys with identical respondents before, during, and after a predictable increase in group tensions in India. Using a combination of survey experiments and direct questions, we find a causal effect of fear on several conflict-perpetuating attitudes among Hindus in terms of increased external prejudice, internal cohesion, and support for extremism.

The paper proceeds as follows: In the next section, we review existing literature. Based on this review, we formulate empirical expectations. After that, we introduce a research design for studying the problem in contemporary India. We then present results from a panel survey conducted during the 2017 Legislative Assembly elections in the northern state of Uttar Pradesh in four systematically selected cities. The article concludes with a discussion and suggestions for future research.

\section{The case for fear}

The drivers of ethnic and religious conflicts have received increased attention since the end of the Cold War. Recent progress on identifying structural conditions most prone to large-scale violence has repeatedly benefited from novel and innovative research designs. Data on actors (Wucherpfennig et al. 2011; Weidmann et al. 2010), infrastructure and geography (Toellefsen et al. 2012), and conflict events (Raleigh and Hegre 2005; Sundberg et al. 2010; Salehyan et al. 2012) have greatly aided the our understanding of the structural determinants of ethnic and religious civil wars. Consequently, disaggregated research on structural conditions most conducive to ethnic civil war has flourished.

Yet, one area of intense research has failed to make comparable empirical leaps: social psychological explanations for micro-motives in intergroup conflict. Fear and insecurity - conceptual cornerstones of scholarly explanations during the 1990s - have not received as much attention as 
explanations rooted in social grievances (Cederman et al. 2013), regime types (Hegre et al. 2001), or weak states (Fearon and Laitin 2003; Lacina 2006). Yet, the theoretical case for fear as a driver of war remains strong.

Posen (1993) identified the "security dilemma" as a conceptual starting point for explaining ethnic civil war. The concept was originally described by Herz (1950) and has become one of the most well-known paradigms for conflict in International Relations. ${ }^{3}$ It centrally contends that a political actor's attempt to increase its own security by preparing for war intimidates its potential adversaries which leads them to prepare for conflict. Especially under anarchy - that is in the absence of a hegemonic mediator that could sanction an aggressor - this constellation can trigger an arms race and eventually an all-out war. According to this line of thought, conflict can emerge even in the absence of threatening intentions (for an review of the classic security dilemma see Tang 2009). According to Posen (1993), this logic easily translates into sub-national standoffs between ethnic groups. Ignatieff (1994:16) stressed that especially the breakdown of central authority boosts existential fears:

Thomas Hobbes would have understood Yugoslavia. What Hobbes would have said, having lived through religious civil war himself, is that when people are sufficiently afraid, they will do anything. There is one type of fear more devastating in its impact than any other, the systemic fear that arises when a state begins to collapse. Ethnic hatred is the result of the terror which arises when legitimate authority disintegrates.

This insight is important, as the Security Dilemma had been originally motivated from a perfectly rational viewpoint to explain interstate wars. Yet, Kaufman (1996:112) maintains that personal fear is essential for intergroup conflict:

The neorealist concept of a security dilemma cannot be mechanically applied to ethnic conflict: anarchy and the possibility of a security threat are not enough to create a security dilemma between communities which may have been at peace for decades. An ethnic security dilemma requires reciprocal fears of group extinction.

With this qualification in mind, fear-centric explanations have been successfully applied to a series of cases. In summarizing her extensive research on riot participation in Nigeria, Scacco

\footnotetext{
${ }^{3}$ The theory was inspired by even earlier work: the arms race model by Richardson ([1919] 1960) is largely compatible with Herz' line of reasoning.
} 
(2012:11) observes that "the inability of the state to offer protection, and the subsequent fear of being targeted, can motivate large numbers of people to participate who might not otherwise choose to riot." Kaufmann (2007) suggests a similar logic played out in Iraq. Suzuki (2011) applied the notion to explaining Hindu-Muslim tensions in India. Wilkinson (2004:32) reviews earlier studies on India and finds the idea of city-level population balances fueling Security Dilemmas to be "ubiquitous".

Why then, has fear as a motivator for intergroup conflict not received more attention during the last two decades? The problem is partially empirical. Recent research on the effects of wartime violence have produced important insights (see Blattman 2009; Bauer et al. 2014; Beber et al. 2014; Grossman et al. 2015; Mironova and Whitt 2016). Yet, associated studies rely on interviews with ex-combatants. While persistent effects of exposure to conflict can undoubtedly be studied in this way, its fleeting nature and possible post-hoc rationalization make fear a poor subject for such designs.

Similarly, lab- and lab-in-the-field experiments have gained popularity in recent empirical studies (see, for example Lerner et al. 2003; Small et al. 2006). ${ }^{4}$ While their scientific contributions cannot be called into question, stylized games are similarly ineligible for the study of acute terror. At best, controlled experiments can elicit the effects of unease on conflict-perpetuating sentiments without veering into unethical territory.

Research on political and economic causes of ethnic civil wars have certainly gained much ground and rely on impressive datasets and sophisticated designs. Yet, they simply lack the granularity needed to measure micro-motives of followers and combatants. With these limitations in mind, it is hardly surprising that the study of fear as a motivator for intergroup conflict has hit an empirical impasse.

As a consequence, the exact role of fear in perpetuating conflict has not been studied sufficiently. However, recent developments in mobile technology entail that studying sentiment in communal conflict in vivo is finally within the grasp of contemporary research. Moreover, lab-induced intimidation has shed light on possible connections between fear, prejudice, and extremism that need to be subjected to real-world tests. In the next section, we combine insights from classic and contemporary social psychology to theorize the role of fear in promoting communal clashes. After that,

\footnotetext{
${ }^{4}$ For a comprehensive review in the field of terrorism studies, see (Arce et al. 2011).
} 
we present results from an longitudinal survey in the Indian state of Uttar Pradesh before, during, and after the contested elections of 2017.

\section{The effects of fear}

As a conceptual starting point, we assume the conflict-perpetuating consequences of fear to be rooted in real-world events. Terrorist attacks across group boundaries, lynchings, and riots can be carried out by small numbers of perpetrators, yet they can intimidate millions. Such low-level political violence poses threats to large numbers of individuals based on their group identities. Generally "threats to physical safety not only elicit a negative (rather than a positive) affective response, they elicit a very specific form of negative affective response: fear (not disgust, not sadness, not pity)" (Neuberg et al. 2011:1044). Especially victims or eye witnesses of physical attacks are likely to be haunted by their experiences. We therefore expect that witnessed or experienced violence leads to increased fear of violence (Hypothesis 1).

Instead of being a direct driver of group-level conflict, fear affects conflict perpetuating attitudes. As Deutsch et al. (2011:274) observes: "Intense fear causes 'tunnel vision,' reducing the range of one's perceptions, thoughts, and choices, risking that we make suboptimal decisions [...] It may save us from immediate danger. However, in the case of complex conflict, fear easily operates malignly." Chief among the derogatory effects of fear is prejudice. Allport (1954) argued that prejudice serves as a cognitive approximation - a "heuristic" (see Gigerenzer and Todd 1999) - in situations where not all necessary information for judging a person is available. Based on the principle of "least effort" (Allport 1954:19), humans rely on past experiences with out-group members for classification (see also Pettigrew 1979).

Importantly, attacks across group boundaries inflict "realistic fears" of being targeted by the extremist perpetrators. Yet these fears are usually accompanied by generalized anxiety toward entire groups (Allport 1954:368). This irrational component of fear makes it a potent amplifier of ordinary prejudice. Recent experimental research supports this line of thinking: ethnocentric prejudices are triggered by moderate increases in individual's level of fear (see Schaller and Neuberg 2012).

We therefore expect that fear for personal safety leads to negative prejudice against the 


\section{out-group (Hypothesis 2).}

Beyond heightened prejudice, fear of imminent violence is likely to cause increased in-group cohesion. A long-standing conjecture - frequently attributed to Simmel (1955) - states that commonly experienced outside aggression translates to increased internal cohesion. In an review of the classic literature, Stein (1976:146) observers that this notion has been widely adopted. With a keen eye for the microdynamics of violence and mobilization during the Kosovo War, Brubaker (2002:167) described how the KLA forged and Albanian support base: attack Serbian forces, count on their indiscriminate retribution, and thereby "ethnicize" the conflict.

Within groups, conflict-induced cohesion has been observed after cessation of hostilities: Blattman (2009) reports that ex-combatants in northern Uganda show increased political participation in their communities. According to Bauer et al. (2014), exposure to conflict during childhood can lead to lasting egalitarian views toward in-groups. Beber et al. (2014) observe that victims of rioting in Sudan display hostile sentiments toward the perpetrating out-group and closer identification with their in-group. Similarly, Bauer et al. (2016) find evidence of a broader spectrum of pro-social behavior in the aftermath of violent conflict: Based on a meta-analysis of more than twenty scholarly studies, the authors conclude that many of the beneficial effects of exposure to wartime violence apply first and foremost to the in-groups of ex-combatants (see also Grossman et al. 2015; Mironova and Whitt 2016).

As the groups of suspected perpetrators are viewed more negatively, the protection offered by the in-group becomes more important. Experimental research underscores this prediction in the laboratory (Fritsche et al. 2011). We therefore expect that fear leads to stronger in-group cohesion (Hypothesis 3), not just in stylized games or long-term legacies of violence, but also in the midst of conflict.

Finally, the ethnocentric views induced by fear could extend into support for violent extremists. Civilians in violent contexts are unable to mitigate the perceived threat of out-group aggression themselves. Thus they might rely on the protection offered by militant actors to maximize their chance of survival (Neuberg and Schaller 2016). Recent cross-sectional studies on correlates of fear suggest this effect (see van Prooijen et al. 2015; Cragin 2014). Therefore, we expect that fear of violence leads to stronger identification with extremist political advocates of the in-group (Hypothesis 4). Figure 1 depicts the proposed mechanism. 


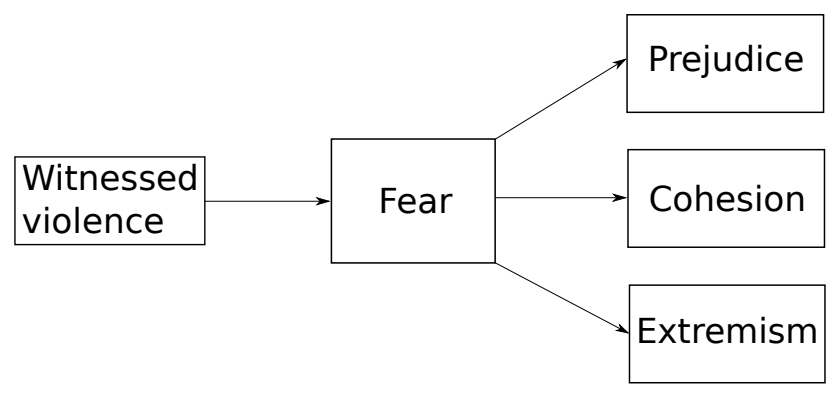

Figure 1: Schematic representation of the theory. Clearly, each outcome variable can contribute to further violence in retaliation for past attacks, thereby escalating group-level conflict and solidifying ethnic and religious identities.

\section{Case selection}

Testing our empirical expectations presents a series of challenges: first and foremost, any experimental exposure to violence is clearly unethical and cannot be part of our research design. Moreover, not all conflict settings are eligible. Full-blown ethnic or religious civil wars and peaceful coexistence are both ineligible, as neither entrenched hatred nor unity are subject to rapid change. Moreover, high-intensity conflicts can quickly render private sentiments irrelevant as paramilitary groups organize and mobilize for large-scale violence. Under such circumstances, personal attitudes are likely difficult to elicit for fear of retribution.

Based on these constraints, we decided to study escalations in an ongoing low-intensity conflict before, during, and after predictable spikes in group-level hostilities. For this setup to work, tensions must be predicted ahead of time in order to facilitate timely measurements of individuallevel sentiments. Yet, conflict escalations along identity lines are rare and hard to predict and postconflict narratives about initial conflict motivations can be biased by eventual conflict outcomes. Moreover, safety requirements for respondents and field teams must be met, as well as logistical standards that enable large-scale public opinion research. Finally, to mitigate expectable panel attrition, small financial incentives need to be generated for keeping respondents in the sample and the case must occur within the funding period of the project.

A case that fits these requirements is political contestation in India that frequently induces religious conflict. We focus on India without suggesting it to be the next Yugoslavia. In contrast to the ongoing conflicts in Iraq and Syria, India's communal conflicts materialize as riots rather than 
genocide, but intense violence between the groups is both a historical reality and a possibility for the future. We build on the fact that the country is subject to an ebb and flow of violence, especially around major elections (see Wilkinson 2004; Brass 2011; Höglund 2009; Daxecker 2014). The cyclical nature of Hindu-Muslim tensions in India entails that the initial conditions of conflict escalations re-emerge more predictably than in other conflicts. Instead of one large-scale eruption of violence that forges cohesion and solidifies group identities on a historical time scale (see AUTHOR), electoral cycles and repeated political tensions change Hindu-Muslim relations regularly but to a less dramatic extent. Due to the cyclical nature of tensions in India, we perceive it as an ideal case to test theoretical expectations. ${ }^{5}, 6$

\section{Religious conflicts in India}

The Indian subcontinent has been home to different ethnic, religious, and linguistic communities for all of recorded history. The current Hindu-Muslim tensions, however, date back to the division of India and Pakistan in 1947 by the British colonial administration (Metcalf and Metcalf 2012:217-223). Political demands for a separate country were mainly pushed by the Muslim minority, who feared Hindu dominance in an independent, democratic India (Pandey 2001:21). By several historical accounts, creating international boundaries to accommodate intermingled religious communities was a massive challenge, but the problem was amplified by rushing new borders into existence: As Britain was struggling economically after having prevailed at an enormous material cost in World War II, bringing home its colonial administration and expeditionary forces was a top priority (see Darwin 2009:519;Pandey 2001:21-25). But by communicating the aggressive timeline for withdrawal and applying a census-based classification of hamlets to draw up the new border, the British created an enormous moral hazard: Out-groups on both sides were driven from their homes in order to shift the location of the future border. As Hindu-Muslim tension

\footnotetext{
${ }^{5}$ We considered alternatives to India and ruled them out based on the above criteria. Countries such as Iraq, Afghanistan, Syria, Libya, and Egypt display increased group-level tensions, but they also provide extremely challenging survey environments. Both respondents and survey teams must not be exposed to any additional risks for the research to be ethically responsible. Moreover, several high-intensity conflicts have long made the transition from primarily political to religious or ethnic civil war. Finally, several conflict countries lack the communications infrastructure required for implementing this survey in an economically feasible manner.

${ }^{6}$ The Ethics Board of < INSTITUTION $>$ has reviewed a proposal for the study. While stressing that the ultimate responsibility for any scientific study lies with the investigator, the board did not object to the proposal given the above considerations, informed consent, a non-invasive questionnaire, and IT security precautions to protect respondents' privacy.
} 
flared up in the countdown to the partition, British hesitance to deploy troops in sufficient numbers had disastrous consequences. Hundreds of thousands lost their lives and many more lost their homes. While the center of the hostilities lay in the northern state of Punjab, riots, lynchings, and forced migration occurred in many areas of both sides of the projected border (Pandey 2001:3639). In the following decades, Hindu-Muslim tensions ebbed and flowed repeatedly. Clashes in 1967 and 1969 led to hundreds of casualties. The year 1992 witnessed a major escalation in the Babri Mosque demolition and the subsequent Bombay Riots that claimed around 900 casualties. More recently, the 2002 and 2006 riots in Gurajat and clashes in Uttar Pradesh in 2013 left more than a thousand dead.

One particularity of the Hindu-Muslim riots in India is that they occur in the context of active political competition: The Bharatiya Janata Party (BJP) was formed in 1980, extending the ideological legacy of Hindu nationalist Rashtriya Swayamsevak Sangh (Metcalf and Metcalf 2012:231 ff.). Today, BJP has a conservative political agenda and a cultural commitment to representing the Hindu majority. The party has simultaneously tried to broaden its appeal among more moderate voters and Muslims in recent years by putting a bigger emphasis on economic development issues.

Whereas the BJP has moved towards the political mainstream, so-called "Gau Raksha" groups have gained wider prominence in the past years. Gau Raksha (literally "cow protection") groups represent a Hindu nationalist movement that defends the cow as the sacred animal in Hinduism. More problematically, these groups are also notorious for their violence against minorities, especially Muslims, who are accused of illegally butchering cattle and of smuggling cattle to states where slaughter is legal. The movement has roots dating back to the late nineteenth century and has played a significant role in defining the Hindu community (Freitag 1980). In recent years, Gau Raksha groups have made headlines in India based on reports of their recurring attacks on minorities and Muslims in particular (Safi 2016; Patel 2017; Abraham 2017).

In contrast to Hindu nationalists, Muslim political representation has taken several forms: Up until 1980, it was mainly organized in the All India Muslim League, but later splintered into regional representations after the league's disintegration. Today, both the center-left Indian National Congress and regional socialist parties have attracted Muslim votes. 


\section{The Legislative Assembly elections of 2017}

Contemporary politics in India are best understood against the backdrop of the 2014 general election that saw a nation-wide victory of the Hindu/right-wing BJP under the leadership of Narendra Modi (see Chandra 2017). In the run-up to the election, Modi was criticized for inciting communal tension between Hindus and Muslims by stating that Muslim migrants from neighboring Bangladesh should "pack their bags" should he win the election. In the immediate aftermath of the BJP's victory, lethal attacks on Muslims in the eastern state of Assam added a grim echo to the populist rhetoric (Aljazeera America 2014)

By several accounts, the situation in Uttar Pradesh prior to the 2017 elections was coming to a head. As local news outlets observed, communal violence in Uttar Pradesh was generally increasing in late 2016, raising fears for a violent election season (The Indian Express 2017a; The Times of India 2017). Data from the Armed Conflict Location and Event Dataset (see Raleigh et al. 2010) generally supports this assessment. As visible in figure 2, Uttar Pradesh is a comparatively unstable state within India and incidents of riots and protests have been increasing over time. Luckily,
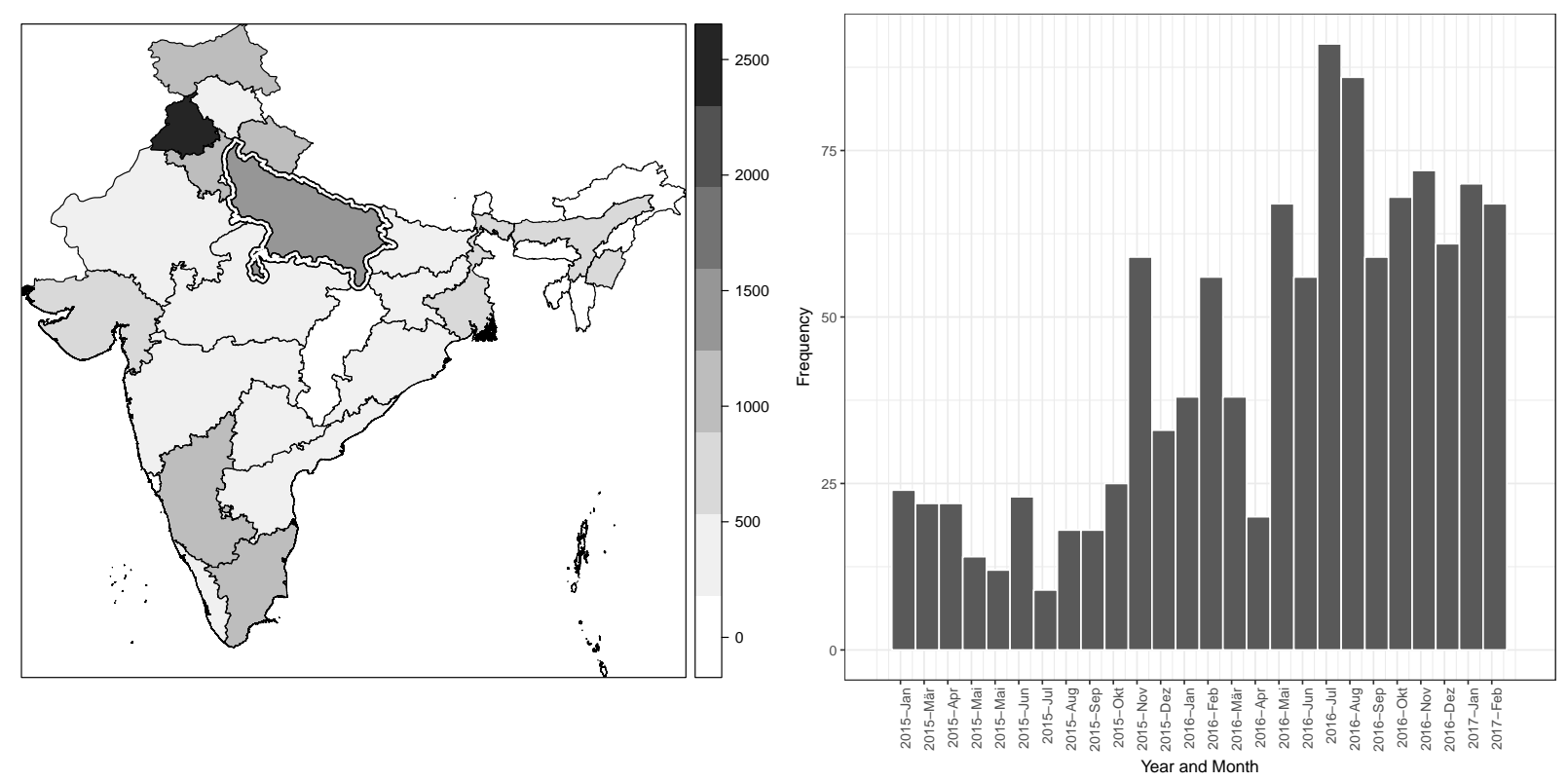

Figure 2: On the left, the distribution of riots and protests according to ACLED can be seen from 2015 to early 2017. The white outlined boundary in the center of the map demarcates Uttar Pradesh (UP). On the right, riots and protests in UP prior and during the 2017 elections obtained from ACLED can be seen. A drastic increase in riots can be seen up until mid-2016, followed by a plateau of about 60 recorded riots and protests per month. 
the expectation of large-scale violence proved ultimately unfounded. As the Hindustan Times put it:

Voters in Uttar Pradesh (UP) and Manipur cast their votes in the ongoing assembly polls on Saturday, with no major incidents of violence being reported by election authorities (Jadid and Samom 2017).

However, violent clashes were reported in several instances by our survey respondents and in the ACLED data collection. Moreover, the election entailed drastic and lasting political change: In a result largely unpredicted by experts and commentators, the BJP scored a historical landslide victory at an overall vote share of $39.7 \%$. Equally impressive was the gain in vote share from the previous election: $24.7 \%$ (see Singh 2017). Initial reactions hailed the BJP victory as a clear indication that the state had moved past its communal division, but critics remain skeptical. An early sign of trouble was prime minister Modi's pick for leading the state: Yogi Adityanath, a Hindu priest and nationalist politician with a track record of anti-Muslim rhetoric (Aljazeera 2017). As we will elaborate below, the unpredicted outcome of the elections in general and Adityanath's appointment in particular could have driven some of our empirical results.

\section{Research design}

We tested our hypotheses using a panel survey in the Indian state of Uttar Pradesh. In each survey wave, we collected information about respondents' experiences and attitudes. The initial survey was conducted face to face, the subsequent waves were conducted using SMS and phone interviews. For tests of our hypotheses, we rely on a mixture of direct questions and survey experiments.

Although the 2017 elections remained largely peaceful, some respondents witnessed isolated intergroup violence between the survey waves. By employing a panel design, we are able to explain changes in intergroup attitudes as a function of previous experiences.

Obviously, the probability of experiencing violence could vary systematically across individuals due to confounding factors. We alleviate this concern by demonstrating that survey responses prior to the election as well as demographic characteristics do not vary significantly across affected and 
unaffected respondents (see section 2 in the supplementary information). Therefore, experiencing violence appears quasi-randomly in the sample. Finally, we analyze the within-respondent variation across survey waves employing respondent- and survey-wave Fixed Effects, thereby ruling out confounding due to constant respondent characteristics.

\subsection{Survey locations}

For the selection of survey sites withing Uttar Pradesh, we implemented nearest-neighbor matching to pair four out of 399 settlements with varying level of reported violence, but otherwise most similar socio-economic characteristics. In the absence of structural observations on the city-level, we had to infer city limits based on Open Street Map (OSM) (OpenStreetMap contributors 2017) in order to integrate multivariate information from different spatial data sources. City limits were modeled by placing geographic buffers around residential streets included in OSM data for UP.

The buffer size of 550 meters was chosen inductively to match modeled boundaries with nighttime light signatures. Overlapping buffers were united into single polygons. From these polygons, the area of the city was inferred. Cumulative night-time light emissions from 2014 - the latest obtainable data point - divided by the area of the settlement served as a proxy for electrification and socioeconomic development (see AUTHOR, National Geophysical Data Center 2014).Cities were joined with 2011 census data available at the district level. ${ }^{7}$ From the census information, rates of unemployment, illiteracy, and percentages of scheduled castes and tribes were coded. Geographically finer information on the local distribution of religious groups was obtained from polling station-level voter registries (see Susewind and Dhattiwala 2014). We included all polling stations from the 2014 general elections which fell into the modeled city limits. Finally, citylevel exposure to violence was constructed from geo-referenced riots and protests from ACLED. To focus explicitly on Hindu-Muslim tensions, we only included incidents that occurred between Hindus and Muslims. Figure 3 displays the modeled city limits and polling stations for the city of Azamgarh.

For this newly constructed multivariate dataset of cities, we used nearest-neighbor matching to identify most similar pairs (see Nielsen 2016). Two matches were retrieved from the sample: First, we drew the best match from the 399 possible survey sites in UP (Lucknow - Azamgarh). Then

\footnotetext{
${ }^{7}$ See http://gadm.org/ and http://censusindia.gov.in/, last accessed April 18, 2018
} 
we removed these sites from the sample and drew the next best match (Meerut - Faizabad). This selection of cities satisfies several criteria: The cities have varying violence exposure but are very similar with regard to other socio-economic characteristics, thereby implementing a most similar systems design. Furthermore, the locations are geographically dispersed within UP, which ensures that different regions are represented and rules out local spillover effects between survey locations.

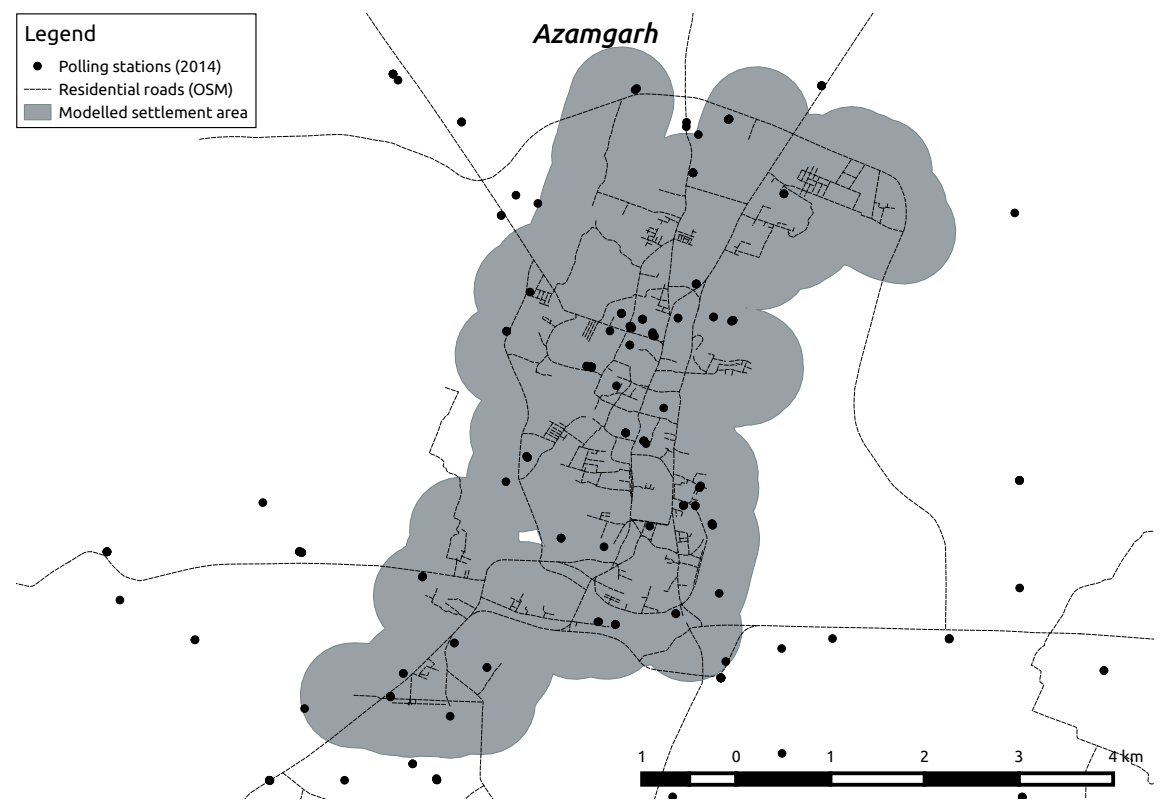

Figure 3: Residential areas, modeled city limits, and polling stations in Azamgarh

\subsection{Survey waves}

To observe changes in sentiments over time, the survey consisted of three waves. We used an initial face-to-face survey with the help of a local survey company to collect a sample of respondents who were willing to participate and provide their mobile phone number for follow-up interviews via SMS or telephone. We employed quota sampling to approximate the distributions of the population in UP based on the 2011 census information. Respondents were compensated with ₹50 ( $\approx$ \$.77) for their participation in each survey wave. The money was transferred in the form of airtime recharges for mobile phones. An initial payment was conducted to add credibility to the promise that respondents would be reimbursed for their efforts. Due to this reimbursement procedure, telephone numbers belonging to the smallest providers that did not offer prepaid transactions and 
malformed numbers were removed from the sample.

After the initial face-to-face survey, the sample consisted of 783 respondents with confirmed numbers. The first survey wave took place between January 15 and February 8, 2017 and was therefore completed prior to the opening of the polls. The second wave conducted via SMS took place between March 8 and March 13 and spanned the weekend the election results were released. Only $14 \%$ of the contacted respondents replied to the invitation via text message. Moreover, the sample of SMS respondents was heavily skewed towards the young and highly educated (see sections 7 and 8 in the supplementary information).

Finally, the third wave was conducted via telephone interviews by local enumerators between April 4 and April 12 2017. Out of the 783 contacted initially, 415 respondents were reached and participated in the survey. In contrast to the second wave via SMS, the demographic characteristics of respondents during the phone-based third wave do not differ systematically from the overall sample. ${ }^{8}$ Therefore, the results reported below draw on the first and third waves. Due to the low response rate for the text messages, we omit the second wave in the main analysis but show corresponding results in section 7 of the supplementary information.

\subsection{Survey design}

Two challenges arose in designing the specific survey questions. First, ensuring the security of respondents and field teams was the top priority. Second, general expectations had to be adapted to local conditions. Therefore, the questionnaire was designed in consultation with the local survey company. This ensured that the field teams were comfortable asking all questions and that nonresponse for fear of possible repercussions was minimal. We used both direct questions which were considered acceptable as well as survey experiments to indirectly infer sentiments (Rosenfeld et al. 2016). The full questionnaire is shown in section 11 of the supplementary information.

We measure our central variable, fear due to violence, by asking whether respondents "fear[ed] for the safety of [themselves] or [their] family because [they] have personally witnessed intercommunal conflict". In order to assess hypothesis 1, we inquired whether respondents had "witnessed inter-communal conflict during the recent election [in Uttar Pradesh]". In order to avoid priming effects, this latter variable was asked at the very end of the survey.

\footnotetext{
${ }^{8}$ See section 8 of the supporting information.
} 
For measuring changes in prejudice against the out-group, we used endorsement experiments to elicit respondents' attitudes without invasive questioning (Bullock et al. 2011). This method has been used successfully to measure support for insurgents in ongoing conflicts in Pakistan and Afghanistan (Blair et al. 2013; 2014; Lyall et al. 2013). Endorsement experiments enable estimation of latent sentiments within groups of respondents without forcing respondents to explicitly state their feelings toward actors. Instead, participants are asked to evaluate an uncontroversial policy in two variants. A treatment group of respondents is told that the policy has been endorsed by a group or political actor. A control group receives the question without endorsement. For an individual response in the treatment group, it is impossible to detect whether a respondent's answer was driven by his or her personal preference for the policy or because the endorsement by a political actor taints the policy. However, as allocation into the groups is randomized, the difference between answers in the treatment and the control group can be used to estimate the average support for an actor. This framework may also be used to establish whether individual-level covariates are associated with a particular endorsement effect. Blair et al. (2013) estimate attitudes toward the endorsing political actor based on average responses in a linear regression framework while Bullock et al. (2011) derive a measurement model using Item Response Theory.

In terms of uncontroversial policies, we asked respondents about their support for air quality initiatives, improved traffic safety, as well as better public transportation. The specific policies were chosen to ensure that adding endorsers would not alter the interpretation of the individual policy's content (see Bullock et al. 2011:370). To investigate out-group prejudice, these policy questions were paired with statements indicating that "leaders of the Hindu community" or "leaders of the Muslim community" supported these initiatives for the treatment groups. We used the difference in responses among the group with the Hindu/Muslim treatment and control group to estimate the association between fear for personal safety and changes in prejudice against the other religious group.

Cohesion was measured by asking whether respondents' "own religious community is very important to [them]". In order to probe respondents' support for extremism due to fear for their personal safety, we asked about their agreement with all major political parties in Uttar Pradesh. While imitating a general public opinion poll, we were mainly interested in actors associated with 
Hindu nationalism, i.e. respondents' attitude towards the Hindu extremist Gau Raksha movement. ${ }^{9}$ To safeguard against the possibility that Gau Raksha support was deemed a sensitive issue, we asked a direct question and additionally included "Gau Raksha group" as a further endorser in the survey experiment described above.

\subsection{Statistical analysis}

Due to the panel structure of our data, we were able to analyze the within-respondent change in survey responses. Specifically, we used the first difference in fear of violence to test hypothesis 1 and linear two-way fixed effects models to analyze hypotheses 3 and 4 . This approach enables us to rule out any confounding due to demographic characteristics of the respondents or any other constant variables. Nevertheless, potential time-varying confounders may affect our results and need to be modeled explicitly: In order to measure community leader influence, we ask respondents whether "leaders from [their] community often say other religious groups create problems". We include this variable in our models to control for a potential confounding effect of withinrespondent changes due to elite interference. Based on the same logic, we control for changes in media consumption of local political news, as journalistic accounts might influence both safety concerns as well as political attitudes.

We test hypothesis 2 (fear leading to prejudice) using the endorsement experiment outlined above. As this inference framework is incompatible with panel data, we use the Bayesian measurement approach proposed by Bullock et al. (2011). The endorsement effect is captured as a shift in the respondents' ideal point induced by the endorsement. Because the survey questions yield ordinal responses, we rely on a partial credit model (Masters 1982; Curtis 2010). To facilitate interpretation, we standardize the coefficients, which enables us to interpret them as changes in terms of the standard deviation of the ideal point. The full model specification and a discussion of the estimation strategy can be found in section 9 of the supplementary information. 
Table 1: Models of within-respondent change between January and April 2017. All dependent variables are 5-point Likert scales, except Model 1, which is the first difference between survey waves. Section 1 in the supplementary information presents substantively identical results from an Ordered Logistic regression model.

\begin{tabular}{|c|c|c|c|c|}
\hline & \multicolumn{4}{|c|}{ Dependent variable: } \\
\hline & FD(Fear) & Religious c & ity important & Support Gau Raksha \\
\hline & (1) & (2) & (3) & (4) \\
\hline Communal violence during election & $\begin{array}{c}0.614^{* *} \\
(0.280)\end{array}$ & & & \\
\hline Fear due to personally experienced violence & & $\begin{array}{c}0.031 \\
(0.022)\end{array}$ & $\begin{array}{l}0.036^{* *} \\
(0.015)\end{array}$ & $\begin{array}{c}0.148^{* * *} \\
(0.054)\end{array}$ \\
\hline Fear x Muslim & & & & $\begin{array}{l}-0.066 \\
(0.120)\end{array}$ \\
\hline Own leaders blame out-group & $\begin{array}{l}0.564^{* *} \\
(0.255)\end{array}$ & $\begin{array}{c}0.097 \\
(0.074)\end{array}$ & $\begin{array}{c}0.066 \\
(0.048)\end{array}$ & $\begin{array}{c}0.099 \\
(0.164)\end{array}$ \\
\hline Daily news consumption & $\begin{array}{l}-0.360 \\
(0.262)\end{array}$ & $\begin{array}{c}-0.175^{* *} \\
(0.079)\end{array}$ & $\begin{array}{c}-0.094^{*} \\
(0.053)\end{array}$ & $\begin{array}{c}-0.654^{* * *} \\
(0.170)\end{array}$ \\
\hline Age & $\begin{array}{c}0.007 \\
(0.008)\end{array}$ & & & \\
\hline Male & $\begin{array}{c}0.249 \\
(0.216)\end{array}$ & & & \\
\hline Muslim & $\begin{array}{c}0.729^{* * *} \\
(0.260)\end{array}$ & & & \\
\hline Income $5-10,000$ & $\begin{array}{l}-0.295 \\
(0.315)\end{array}$ & & & \\
\hline Income $10-15,000$ & $\begin{array}{c}-0.606^{*} \\
(0.336)\end{array}$ & & & \\
\hline Income $15-25,000$ & $\begin{array}{c}0.895^{* * *} \\
(0.301)\end{array}$ & & & \\
\hline Income $25-50,000$ & $\begin{array}{l}0.621^{*} \\
(0.357)\end{array}$ & & & \\
\hline Income over 50,000 & $\begin{array}{c}1.344 \\
(0.877)\end{array}$ & & & \\
\hline Lucknow & $\begin{array}{l}-0.209 \\
(0.290)\end{array}$ & & & \\
\hline Faizabad & $\begin{array}{c}-0.518^{*} \\
(0.280)\end{array}$ & & & \\
\hline Azamgarh & $\begin{array}{c}-0.651^{* *} \\
(0.316)\end{array}$ & & & \\
\hline Constant & $\begin{array}{l}-0.589 \\
(0.526)\end{array}$ & & $\begin{array}{c}4.634^{* * *} \\
(0.079)\end{array}$ & \\
\hline Hypothesis & 1 & 3 & 3 & 4 \\
\hline Two-way FE & No & Yes & No (RE) & Yes \\
\hline Observations & 411 & 823 & 823 & 721 \\
\hline $\mathrm{R}^{2}$ & 0.132 & 0.030 & 0.018 & 0.094 \\
\hline
\end{tabular}




\section{Empirical results}

To evaluate our first hypothesis, we calculate the change (first difference) in a person's reported fear between the first and the last survey wave. Positive values indicate increased fear, negative values show that respondents have become less fearful between January and April of 2017. We use a linear regression model to test whether respondents who experienced election violence report a stronger increase in safety concerns. Table 1 reports the corresponding results. The sections 3 to 6 in the supplementary information show robustness checks with additional specifications.

Model 1 lends support to hypothesis 1. On average, the fear of respondents who have experienced communal violence during the elections increased by more than half a point on the Likert scale between January and April 2017. Confidence in the model is underscored by the estimated effects of other variables that are consistent with the general developments during the 2017 election: Muslim respondents' fear increased, on average, possibly mirroring their worries after the BJP's landslide victory and the appointment of Yogi Adityanath as UP's chief minister. The results also indicate that perceptions might be influenced from the top down by political leaders. Respondents who report that leaders of their own community blamed the other religious group for problems appear more fearful after the election.

In addition to these individual-level covariates, the variation in response patterns between survey locations corresponds to the reported violence in Uttar Pradesh during the election as documented by the Armed Conflict Location and Event Dataset (Raleigh et al. 2010). During the fortunately relatively peaceful election process, Faizabad and Azamgarh witnessed no violent events. Consequently, the average reported fear among respondents in both cities decreased significantly. In contrast, Lucknow and Meerut (the reference category in Model 1), both saw some communal clashes during the election period. Fear of violence among respondents in these cities remained high. Overall, the results suggest that the survey question correctly measures short-term variation in safety concerns that is consistent with reported levels of violence. Hence, we use the variation in the fear due to violence variable to evaluate our remaining hypotheses.

\footnotetext{
${ }^{9}$ Due to the fractured Muslim representation, we restricted our analysis of extremist positions to Hindu nationalism.
} 
Figure 4: Estimated subgroup-specific endorsement effects by leaders from the opposite religious community.

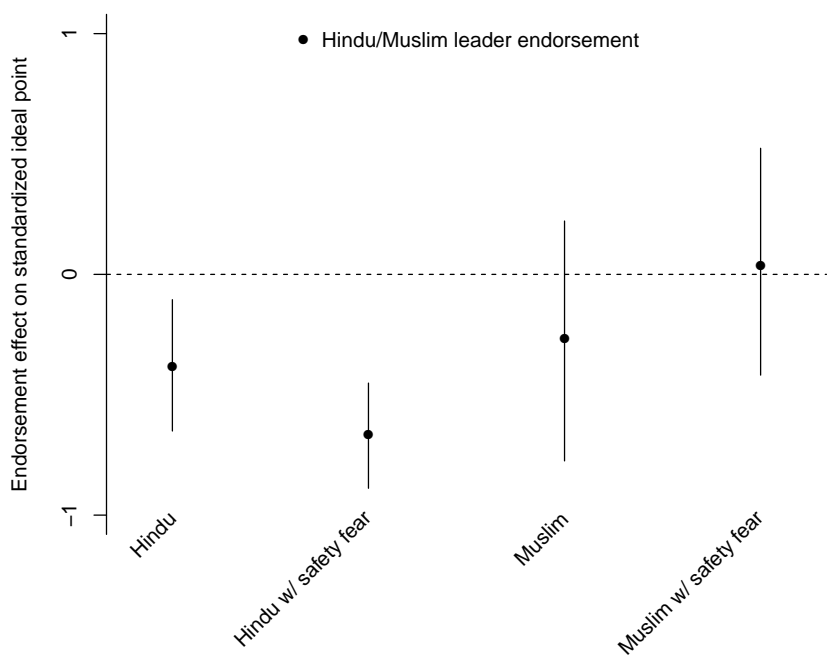

\section{Fear and prejudice}

In order to evaluate hypothesis 2, suggesting that fear increases prejudice, we use the Bayesian estimation framework introduced in section 5.4. As described above, we asked respondents about uncontroversial policies. A control group received only the policy questions. A randomly selected treatment group received a variant of these questions where either "Muslim community leaders" (for Hindu respondents) or "Hindu community leaders" (for Muslim respondents) have voiced support for the policy. Due to the random assignment of treatment, we are able to use the difference in answers as an estimate of prejudice against an endorser.

We model an endorsement effect which varies with fear. ${ }^{10}$ In order to allow for varying effects across religious groups, we estimate a separate effect for Hindus and Muslims in the sample. Figure 4 provides the estimated treatment effects for the endorsement model and displays the combined effect for each subgroup.

Figure 4 suggests that the predicted pattern seems to be present among Hindu respondents, but not among Muslims. The endorsement by "Muslim community leaders" reduces the respondents'

\footnotetext{
${ }^{10}$ To reduce the number of groups in this analysis, we define fear as a dummy variable which indicates that respondents agree or strongly agree with the statement: "I fear for the safety of myself and my family, because I have personally experienced violence."
} 
ideal point strongly, i.e. by approximately a third of one standard deviation. Among Hindus with safety concerns, this negative effect becomes substantively larger: The shift in ideal point is almost two thirds of one standard deviation. Hence, Hindus are much more inclined to disapprove of a policy if the policy is endorsed by Muslim leaders. This negative prejudice is doubled if the respondents experience fear because they witnessed or experienced religious violence. ${ }^{11}$ However, Muslim respondents do not display a corresponding pattern. The posterior distribution for the combined effect in both Muslim subgroups includes zero and does not show the predicted pattern. If anything, fearful Muslim respondents appear to be slightly more neutral towards Hindu community leaders than Muslims without fear of violence, but the estimation uncertainty is too large to support substantive interpretation.

The ambiguous findings for Muslim respondents might be due to the imprecision of the endorsement experiment in these contexts. In Hindu-dominated Uttar Pradesh, the term "Hindu community leaders" may be much less precise than the term "Muslim community leaders", which is more readily associated with Imams or other religious actors. This limitation notwithstanding, the clear endorsement effect among Hindus lends some support to our hypothesis that fear for personal safety reinforces prejudice.

\section{Fear and cohesion}

To test our prediction that fear increases cohesion (H3), we analyze how respondents perceive their own religious community. Overall, there is very little variance in reported importance of religious communities among respondents. About 96 percent agree or strongly agree that their religious community is very important to them, of which 80 percent fall in the "strongly agree" category. Given that there is little variance, any estimated coefficient will be very small.

In a two-way fixed effects model of fear due to witnessed or experienced violence and group identification, the estimated effect is positive, but not statistically significant (Model 2 in Table 1). However, this might be due to the inefficiency of fixed effects estimates and the small variance

\footnotetext{
${ }^{11}$ Previous research on communal conflict in India suggests that the influence of leaders is key in driving prejudice against the out-group (cf. Wilkinson 2004). An additional analysis described in the supporting material (section 4) supports this finding: Hindus who report that their community leaders blame Muslims for existing problems exhibit a strong negative endorsement effect. Although controlling for this leader influence reduces the direct effect of fear due to violence somewhat, the posterior probability of a prejudice enforcing effect of safety fears remains high at an estimated 90 percent.
} 
in the outcome variable. In line with this reasoning, a random effects (RE) model yields a significant increase in the reported importance of respondents' religious communities when fear of violence increases (Model 3 in Table 1). The validity of the random effects model is backed up by a Hausman test. The test fails to reject the null hypothesis that the RE model is consistent $\left(\chi^{2}(3 d f)=2.86, p=0.414\right)$. This underscores the interpretation that the RE model is to be preferred. The insignificant coefficient in the fixed effects model thus seems to be due to the asymptotic inefficiency of the fixed effects estimator. Consequently, the results support hypothesis 3 and indicate that respondents who become more fearful due to communal violence are indeed more attached to their own in-group. The estimates also highlight that concerns over violent clashes can reinforce in-group identities even in situations where group membership is already salient.

\section{Fear and support for extremism}

Hypothesis 4 predicts fear to cause increased support of extremism. We test this by measuring support for the Hindu extremist Gau Raksha movement. Since Gau Raksha groups are notorious for their violence against minorities, we expect the association to vary between Hindu and Muslim respondents. While fear of violence should increase Hindu support for Gau Raksha (in-group), this effect should not apply to Muslim respondents.

Model 6 indicates that increased safety fears are associated with stronger support for the Gau Raksha movement. Furthermore, as expected, the estimated interaction coefficient for Muslim respondents is negative. However, interaction effects are inherently difficult to interpret and insignificant coefficients do not imply insignificant substantive effects. Figure 5 depicts the estimated substantive effect of safety fears for both Hindus and Muslims. Our estimates indicate that Hindu respondents become more likely to voice support for Gau Raksha with increasing safety fears. This finding underscores Hypothesis 4 that fear breeds support for extremists groups. Furthermore, as expected, we find no corresponding effect among Muslims, for whom Gau Raksha groups represent actors affiliated with the out-group. However, the estimation uncertainty for Muslims is extremely large.

We cautiously suggest two explanations for the large estimation uncertainty among Muslims. First, the number of Muslim respondents in our sample is substantively smaller than that of Hindu 
Figure 5: Estimated subgroup-specific effect of safety fears on support for Gau Raksha groups (based on Table 1).

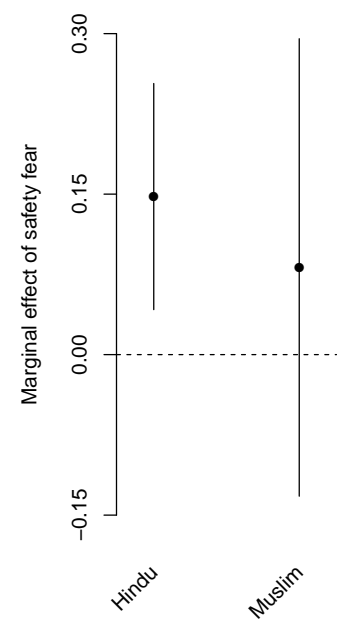

respondents, which decreases the statistical power. Moreover, the response pattern among Muslims might be affected by some misreporting. Our enumerators described how during the telephone surveys after the elections, some Muslim respondents were reluctant to answer questions about the outcome of the election and indicated that they were anxious about future political developments. As the new BJP government enacts symbolic policies which reflect Hindu nationalist and Gau Raksha-related values (The Indian Express 2017b; Prabhu 2017; Rashid 2017; Safi 2017), some Muslims concerned about their safety might be more inclined to pay lip service to the Gau Raksha movement, generating a very heterogenous response pattern. In line with this posthoc explanation, we observe a substantive increase in the average support for Gau Raksha groups between the two survey waves.

We cross-validate this interpretation with the results of our endorsement experiment. The pattern for Gau Raksha endorsements are ambiguous (Figure 6). The posteriors for all subgroup effects cluster around zero, indicating no effect. Only the effect for Muslim respondents who fear for their safety trends moderately into the negative range. However, due to the relatively small number of Muslims in the sample, the estimated credible interval is very large. In contrast to the analysis of the direct question, which supported our hypothesis, we find no endorsement effect for Gau Raksha 
Figure 6: Estimated subgroup-specific endorsement effects by Gau Raksha Groups.

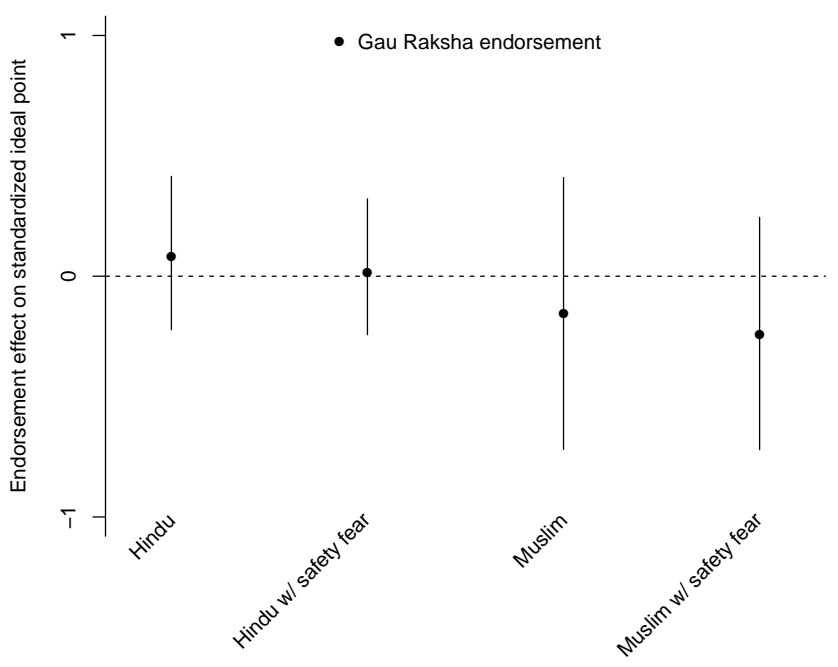

groups among the Hindu population.

The different results for the endorsement question relative to the direct question among Hindu respondents is likely due to two limitations of our endorsement experiment. First, the support for all policies is extremely high, thus leaving virtually no opportunity for a positive endorsement effect. Hence, positive effects will be biased to zero. Keeping these limitations in mind, our analysis reveals mixed evidence in support of our hypothesis that fear drives up support for extremist actors.

\section{Discussion and conclusion}

In this paper, we have combined insights from conflict studies and social psychology to craft an explanation of how fear fuels hostilities between groups. We have taken great care to ensure that the results yield generalizable insights. Survey locations were chosen based on a quantitative mostsimilar systems design and the sample of respondents is representative of the state.

Our analysis presents substantive support for both prejudice formation and increased in-group cohesion as a function of fear. Based on two-way fixed effects estimation for the direct questions, we were able to prevent all time-invariant confounders and survey wave differences from driving the results. Based on survey experiments, we were able to measure prejudice against Muslim 
endorsers among Hindus that would otherwise be biased by social desirability considerations.

We also find mixed evidence that fear increases support for extremist actors from the own ingroup. When asked using a direct question, we observed that Hindus become more supportive of Hindu nationalist groups once they fear for their safety, controlling for respondent and survey wave fixed effects. However, we were unable to find the same pattern in our endorsement experiment, possibly due to ceiling effects for our endorsement question.

From a larger perspective, our results indicate that the social psychology of individual attitudes and group dynamics during conflict is a fruitful analytical perspective which has largely been overlooked during the past decade. Both observational insights from the 1990s and stylized lab experiments suggested that fear may be a driving element of conflict dynamics. However, prior to this study, the empirical relevance of this process had not been demonstrated in ongoing conflicts, due to the lack of quasi-experimental individual-level research designs. Harnessing recent innovation in mobile communication and electronic payment technologies, we have taken the first step to fill this gap and implemented a test of how fear drives conflictual attitudes in episodes of political violence. Further development of such technologies will entail that victims, perpetrators, and tacit supporters of political violence will be increasingly within reach of large-scale electronic survey research. This could enable international comparisons to assess whether the mechanisms described in this study apply globally.

\section{References}

Bobins Abraham. After muslim man was killed by a 'gau rakshak' gang in haryana, sc asks why shouldn't these groups be banned. India Times, April 07, 2018, 2017. http://www . indiatimes . com/news/india/after-muslim-man-was-killed-by-agau-rakshak-gang-in-haryana-sc-asks-why-shouldn-t-these-groups-be-banned275097.html, retrieved last on April 12, 2019.

Aljazeera. Modi bjp picks firebrand to head india's uttar pradesh. Aljazeera, 18 March 2018, 2017. http://www.aljazeera.com/news/2017/03/modi-bjp-picks-firebrand-headindia-uttar-pradesh-170318185051135.html, retrieved last on April 8, 2019.

Aljazeera America. Death toll rises in india election violence. Aljazeera America, May 3, 2014 10:47AM ET, 2014. http://america.aljazeera. com/articles/2014/5/3/indiaethnic-violence.html, retrieved last on April 8, 2019. 
Gordon W. Allport. The Nature of Prejudice. Basic Books, 1954.

Daniel G Arce, Rachel TA Croson, and Catherine C Eckel. Terrorism experiments. Journal of Peace Research, 48(3):373-382, 2011.

Michal Bauer, Alessandra Cassar, Julie Chytilová, and Joseph Henrich. War's enduring effects on the development of egalitarian motivations and in-group biases. Psychological Science, 25(1): 47-57, 2014.

Michal Bauer, Christopher Blattman, Julie Chytilová, Joseph Henrich, Edward Miguel, and Tamar Mitts. Can war foster cooperation? The Journal of Economic Perspectives, 30(3):249-274, 2016.

Bernd Beber, Philip Roessler, and Alexandra Scacco. Intergroup violence and political attitudes: Evidence from a dividing sudan. The Journal of Politics, 76(3):649-665, 2014.

Graeme Blair, C. Christine Fair, Neil Malhotra, and Jacob N. Shapiro. Poverty and support for militant politics: Evidence from pakistan. American Journal of Political Science, 57(1):30-48, 2013. ISSN 00925853. doi: 10.1111/j.1540-5907.2012.00604.x.

Graeme Blair, Kosuke Imai, and Jason Lyall. Comparing and combining list and endorsement experiments: Evidence from afghanistan. American Journal of Political Science, 58(4):10431063, 2014. ISSN 00925853. doi: 10.1111/ajps.12086.

Christopher Blattman. From violence to voting: War and political participation in uganda. American Political Science Review, 103(2):231-247, 2009.

Paul R Brass. The production of Hindu-Muslim violence in contemporary India. University of Washington Press, 2011.

Rogers Brubaker. Ethnicity without groups. European journal of sociology, 43(02):163-189, 2002.

Will Bullock, Kosuke Imai, and Jacob N. Shapiro. Statistical analysis of endorsement experiments: Measuring support for militant groups in pakistan. Political Analysis, 19(4):363-384, 2011. ISSN 1047-1987. doi: 10.1093/pan/mpr031.

Dustin Carpenter, Tova Fuller, and Les Roberts. Wikileaks and iraq body count: the sum of parts may not add up to the whole-a comparison of two tallies of iraqi civilian deaths. Prehospital and Disaster Medicine, pages 1-7, 2013.

Lars-Erik Cederman, Kristian Skrede Gleditsch, and Halvard Buhaug. Inequality, Grievances, and Civil War. Cambridge University Press, 2013.

Kanchan Chandra. Who is narendra modi? Foreign Affairs, 2017.

R Kim Cragin. Resisting violent extremism: A conceptual model for non-radicalization. Terrorism and Political Violence, 26(2):337-353, 2014.

S. McKay Curtis. Bugs code for item response theory. Journal of Statistical Software, 36(Code Snippet 1), 2010. ISSN 1548-7660. doi: 10.18637/jss.v036.c01. 
John Darwin. The Empire Project: The Rise and Fall of the British World-System, 1830-1970. Cambridge University Press, 2009.

Ursula E Daxecker. All quiet on election day? international election observation and incentives for pre-election violence in african elections. Electoral Studies, 34:232-243, 2014.

Morton Deutsch, Peter T Coleman, and Eric C Marcus. The handbook of conflict resolution: Theory and practice. John Wiley \& Sons, 2011.

James D. Fearon and David D. Laitin. Ethnicity, insurgency and civil war. American Political Science Review, 97(1):75-90, 2003.

Sandria B. Freitag. Sacred symbol as mobilizing ideology: The north indian search for a"hindu" community. Comparative Studies in Society and History, 22(4):597, 1980. ISSN 0010-4175. doi: 10.1017/S0010417500009567.

Immo Fritsche, Eva Jonas, and Thomas Kessler. Collective reactions to threat: Implications for intergroup conflict and for solving societal crises. Social Issues and Policy Review, 5(1):101136, 2011.

Gerd Gigerenzer and Peter M. Todd. Simple Heuristics That Make Us Smart. Oxford University Press, 1999.

Donald P. Green and Rachel L. Seher. What role does prejudice play in ethnic conflict? Annual Review of Political Science, 6(1):509-531, 2003.

Guy Grossman, Devorah Manekin, and Dan Miodownik. The political legacies of combat: Attitudes toward war and peace among israeli ex-combatants. International Organization, 69(04): 981-1009, 2015.

H. Hegre, T. Ellingsen, S. Gates, and N. P. Gleditsch. Toward a democratic civil peace? democracy, political change, and civil war, 1816-1992. American Political Science Review, 95(1):33-48, 2001.

John Herz. Idealist internationalism and the security dilemma. World Politics, 2(2), 1950.

Kristine Höglund. Electoral violence in conflict-ridden societies: concepts, causes, and consequences. Terrorism and political violence, 21(3):412-427, 2009.

Murtaza Hussain. Islamic state's goal: "eliminating the grayzone" of coexistence between muslims and the west. The Intercept, November 17 2015, 6:39 p.m., 2015. https://theintercept.com/2015/11/17/islamic-states-goal-eliminatingthe-grayzone-of-coexistence-between-muslims-and-the-west/, retrieved last May $22,2018$.

Michael Ignatieff. Blood and belonging: Journeys into the new nationalism. Macmillan, 1994. 
Abdul Jadid and Sobhapati Samom. Up, manipur witness improved turnout as polls remain peaceful. Hindustan Times, Mar 04, 2018 23:54 IST, 2017. http: //www.hindustantimes .com/india-news/up-manipur-witness-improved-turnoutas-polls-remain-peaceful/story-1uay7RKo3FEZZuio6CM83I.html, retrieved last on April 8, 2019.

Stuart J Kaufman. An 'international' theory of inter-ethnic war. Review of International Studies, 22(2):149-171, 1996.

Chaim Kaufmann. A security dilemma: Ethnic partitioning in iraq. Harvard International Review, 28(4):44, 2007.

Bethany Lacina. Explaining the severity of civil wars. Journal of Conflict Resolution, 50(2):276, 289, 2006.

David A Lake and Donald Rothchild. Containing fear: The origins and management of ethnic conflict. International security, 21(2):41-75, 1996.

Jennifer S Lerner, Roxana M Gonzalez, Deborah A Small, and Baruch Fischhoff. Effects of fear and anger on perceived risks of terrorism: A national field experiment. Psychological science, 14(2):144-150, 2003.

Jason Lyall, Graeme Blair, and Kosuke Imai. Explaining support for combatants during wartime: A survey experiment in afghanistan. American Political Science Review, 107(04):679-705, 2013. ISSN 0003-0554. doi: 10.1017/S0003055413000403.

Geoff N. Masters. A rasch model for partial credit scoring. Psychometrika, 47(2):149-174, 1982. ISSN 0033-3123. doi: 10.1007/BF02296272.

Barbara D. Metcalf and Thomas R. Metcalf. A Concise History of Modern India. Cambridge University Press, 2012.

Vera Mironova and Sam Whitt. Social norms after conflict exposure and victimization by violence: Experimental evidence from kosovo. British Journal of Political Science, pages 1-17, 2016.

National Geophysical Data Center. Dmsp-ols nighttime lights time series, 2014. URL http: //ngdc.noaa.gov/eog/dmsp/downloadV4composites.html.

Steven L Neuberg and Mark Schaller. An evolutionary threat-management approach to prejudices. Current Opinion in Psychology, 7:1-5, 2016.

Steven L Neuberg, Douglas T Kenrick, and Mark Schaller. Human threat management systems: Self-protection and disease avoidance. Neuroscience \& Biobehavioral Reviews, 35(4):10421051, 2011.

Richard A. Nielsen. Case selection via matching. Sociological Methods \& Research, 45(3):569597, 2016. ISSN 0049-1241. doi: 10.1177/0049124114547054.

OpenStreetMap contributors. Planet dump retrieved from https://planet.osm.org . https://www . openstreetmap.org, 2017. 
Gyanendra Pandey. Remembering Partition: Violence, Nationalism and History in India. Cambridge University Press, 2001.

Aakar Patel. Stiffer cow slaughter laws may save cattle but what about people? The Times of India - Blogs, May 28, 2018, 12:05 am IST, 2017. http://blogs.timesofindia.indiatimes. com/aakarvani/stiffer-cow-slaughter-laws-may-save-cattle-but-what-aboutpeople/, retrieved last on April 12, 2019.

Thomas F. Pettigrew. The ultimate attribution error: Extending allport's cognitive analysis of prejudice. Personality and Social Psychology Bulletin, 5(4):461-467, 1979.

Barry Posen. The security dilemma and ethnic conflict. Survival, 35(1):27-47, 1993.

Maya Prabhu. India's battle over buffalo meat. Aljazeera, 16 May 2018, 2017. http://www . aljazeera. com/indepth/features/2017/05/india-battle-buffalomeat-170511102459372.html, retrieved last on April 12, 2019.

Clionadh Raleigh and Håvard Hegre. Introducing acled: An armed conflict location and event dataset, 2005.

Clionadh Raleigh, Andrew Linke, Håvard Hegre, and Joakim Karlsen. Introducing acled: an armed conflict location and event dataset. Journal of Peace Research, 47(5):651-660, 2010.

Omar Rashid. U.p. deploys ambulances for cows. The Hindu, May 01, 2018 23:05 IST, 2017. http://www. thehindu.com/news/national/other-states/an-ambulance-forcows-in-uttar-pradesh/article18347862. ece, retrieved last on April 12, 2019.

Lewis F. Richardson. Arms and Insecurity: A Mathematical Study of the Causes and Origins of War. Boxwood Press, 1960.

Bryn Rosenfeld, Kosuke Imai, and Jacob N. Shapiro. An empirical validation study of popular survey methodologies for sensitive questions. American Journal of Political Science, 60(3): 783-802, 2016. ISSN 00925853. doi: 10.1111/ajps.12205.

Michael Safi. On patrol with the hindu vigilantes who would kill to protect india's cows. The Guardian, Thursday 27 October 201606.51 BST, 2016. https: //www. theguardian.com/world/2016/oct/27/on-patrol-hindu-vigilantessmuggling-protect-india-cows-kill, retrieved last on April 12, 2019.

Michael Safi. Blues and moos: Indian state launches cow ambulance service. The Guardian, May 8, 2018, 2017. https://www.theguardian.com/world/2017/may/08/cow-ambulancesindias-latest-scheme-to-protect-revered-animal, retrieved last on April 12, 2019.

Idean Salehyan, Cullen S Hendrix, Jesse Hamner, Christina Case, Christopher Linebarger, Emily Stull, and Jennifer Williams. Social conflict in africa: A new database. International Interactions, 38(4):503-511, 2012.

Alexandra Scacco. Anatomy of a Riot: Participation in Ethnic Violence in Nigeria. 2012. 
Mark Schaller and Steven L Neuberg. Danger, disease, and the nature of prejudice (s). In Advances in experimental social psychology, volume 46, pages 1-54. 2012.

Georg Simmel. Conflict and The Web of Group-Affiliations. The Free Press, 1955.

Sinderpal Singh. The modi 'wave': Implications of uttar pradesh state elections. 2017.

Deborah A Small, Jennifer S Lerner, and Baruch Fischhoff. Emotion priming and attributions for terrorism: Americans' reactions in a national field experiment. Political Psychology, 27(2): 289-298, 2006.

Arthur A Stein. Conflict and cohesion: A review of the literature. Journal of conflict resolution, 20(1):143-172, 1976.

Ralph Sundberg, Methilda Lindgren, and Ausra Padskocimaite. Ucdp ged codebook version 1.52011. Available online at http://www.ucdp.uu.se/ged/, 2010.

Raphael Susewind and Raheel Dhattiwala. Spatial variation in the âĂIJmuslim voteâĂ ì gujarat and uttar pradesh, 2014 (replication data). 2014.

Akisato Suzuki. Partition and conflict transformation in india: Pakistan and cyprus. Federal Governance, 8(2):54-62, 2011.

Shiping Tang. The security dilemma: A conceptual analysis. Security studies, 18(3):587-623, 2009.

The Indian Express. Rise in communal violence incidents in uttar pradesh in 2016, decrease in overall numbers: Govt. The Indian Express, February 7, 2018 1:18 pm, 2017a. http://indianexpress. com/elections/in-2016-rise-in-communal-violenceincidents-in-uttar-pradesh-decrease-in-overall-numbers-4511876/, retrieved last on April 8, 2019.

The Indian Express. Mere sloganeering not enough, people should step up: Yogi adityanath on cow protection. The Indian Express, April 30, 2018 7:57 pm, 2017b. http://indianexpress . com/article/india/mere-sloganeering-not-enoughpeople-should-step-up-yogi-adityanath-on-cow-protection/, retrieved last on April 12, 2019.

The Times of India. Rise in communal violence in poll-bound up, kiren rijiju says. The Times of India, Feb 7, 2018, 10.37 PM IST, 2017. http://timesofindia.indiatimes. com/elections/assembly-elections/uttar-pradesh/news/rise-in-communalviolence-in-poll-bound-up-kiren-rijiju-says/articleshow/57025941.cms, retrieved last on April 8, 2019.

Andreas Toellefsen, Håvard Strand, and Halvard Buhaug. Prio-grid: A unified spatial data structure. Journal of Peace Research, 49(2):363-374, 2012.

Jan-Willem van Prooijen, André PM Krouwel, Max Boiten, and Lennart Eendebak. Fear among the extremes: How political ideology predicts negative emotions and outgroup derogation. Personality and social psychology bulletin, 41(4):485-497, 2015. 
Nils B. Weidmann, Doreen Kuse, and Kristian Skrede Gleditsch. The geography of the international system:the cshapes dataset. International Interactions, 36(1):86-106, 2010.

Steven I. Wilkinson. Votes and Violence. Cambridge University Press, 2004.

Lawrence Wright. The Looming Tower: Al-Qaeda and the Road to 9/11. Vintage Books, 2007.

Julian Wucherpfennig, Nils. B. Weidmann, Luc Girardin, Lars-Erik Cederman, and Andreas Wimmer. Politically relevant ethnic groups across space and time: Introducing the geoepr dataset. Conflict Management and Peace Science, 28(5):423-437, 2011. 